\title{
Learning Experience in Designing a Hydraulic Bulge Test Setup for Material Properties Characterization
}

\section{Mr. Moses Sylvester jaia Jr}

Moses Sylvester Jaia Jr's Descriptive Bio: Moses Sylvester Jaia Jr. graduated in Spring 2014 with a Bachelor of Science Degree in Engineering with Mechanical Engineering Specialization from the University of Maryland Eastern Shore (UMES). For his Senior Design Project, Mr. Jaia designed a Bulge Test Setup for material properties characterization up to failure under biaxial stress state. Mr. Jaia used Solidworks and Abaqus extensively to complete his Senior Design Project. During his undergraduate studies, Mr. Jaia completed an internship with Safran Labinal Salisbury and worked as a Teaching Assistant at UMES. Mr. Jaia is currently pursuing his Masters Degree in Mechanical Engineering at the University of Maryland Baltimore County (UMBC).

\section{Dr. Payam Matin, University of Maryland, Eastern Shore}

Dr. Payam Matin is currently an Associate Professor in the Department of Engineering and Aviation Sciences at the University of Maryland Eastern Shore (UMES), Princess Anne, Maryland. Dr. Matin has received his Ph.D. in Mechanical Engineering from Oakland University, Rochester, Michigan in May 2005. He has taught a number of courses in the areas of mechanical engineering and aerospace at UMES. He has served as departmental ABET committee chair through a successful accreditation visit in Fall 2012. Dr. Matin's research has been mostly in the areas of Computational Mechanics and Experimental Mechanics with applications in Solid Mechanics, Plasticity and Sheet Metal Forming. Dr. Matin has published more than 25 peer-reviewed journal and conference papers. Dr. Matin is the recipient of NSF MRI award as a Co-PI. Dr. Matin worked in Automotive industry for Chrysler Corporation from 2005 to 2007. He Joined UMES in August 2007. He is affiliated with ASME and ASEE professional societies 


\section{Learning Experience in Designing a Hydraulic Bulge Test Setup for Material Properties Characterization}

Tensile test has been widely used in both industry and academia for material properties characterization despite its shortcoming in non-uniform plastic deformation zone due to necking phenomena. While tensile testing delivers acceptable results for most applications, more accurate characterization is desired for metal forming processes in which plastic deformation plays a crucial rule. As an alternative, hydraulic bulge test can be utilized to characterize materials properties without necking effects. In a bulge test, a flat sheet metal specimen is deformed by pressurized water into a cylindrical die in a shape of a spherical bulge. The objective of this project is to provide learning experience to a team of students to design a bulge test set up in a senior design project framework. With pre-defined sets of educational objectives, the project is defined for the students. The design requirements and design constraints are articulated at the start of the project. Advance High Strength Steels (AHSS) particularly TRIPs (Transformation Induced Plasticity Steels) are targeted as the material of interests for design purposes. Students have learned about fundamentals of plasticity and forming simulation with ABAQUS to calculate the pressure needed to conduct a successful bulge test on the material of interest. Students have used fundamentals of mechanics of materials and FEM simulation to design the bulge test setup for the calculated pressure. Pressure and position sensors are considered in the setup to estimate the level of stress and strain, respectively, at different stages of plastic deformation for material properties characterization. The authors present how fundamentals of engineering are utilized throughout the course of the project. The learning outcomes of the project are also discussed, which indicate that the educational objectives of the project have been met.

\section{Introduction}

Material properties are the starting block for the design and analysis of most structures. Tensile test is widely used in both industry and academia to determine mechanical properties of materials. Tensile test is preliminary used to determine the stress-strain relationship (graph) in many engineering materials including metals [1]. In a tensile test, a dog-bone tensile specimen is stretched uniaxially until fracture occurs. In a tensile test, the stress is calculated based on the force measured by a load cell during testing. The strain is calculated based on the change in length measured by an extensometer. Tensile testing delivers accurate results in the elastic deformation zone and only a part of plastic deformation zone where deformation is uniform. At the onset of necking where the plastic deformation becomes non-uniform, tensile testing does not deliver accurate results. While tensile testing results are applicable for most of applications, more accurate characterization is desired for the applications such as metal forming processes or crash simulation where plastic deformation plays a major rule.

Hydraulic bulge testing can be utilized as an alternative for more accurate materials characterization. In a bulge test, a flat thin disc-shape sheet metal blank is clamped around its 
circumference and then subjected to an increasing hydraulic pressure applied to one side [2]. The hydraulic pressure deforms the specimen in a nearly spherical shape with full symmetry that is associated with a biaxial deformation. The stress is calculated based on the level of the pressure applied. The strain is calculated based on the height of the bulge measured during testing. In a bulge test, the necking phenomenon does not appear during testing due to the biaxial deformation. This allows for the bulge test to be carried out without necking effects for the entire plastic deformation zone up to the failure and deliver more accurate results.

Figure 1 shows the main components of a bulge test setup. In general, the main components are the lower die, the upper die (or the blank holder), sheet metal specimen, clamping system, sealing and pressure delivery system. The sheet metal specimen is placed on the lower die. As a blank holder, the upper die is placed on the sheet metal specimen. A clamping system tightens the upper die to the lower die to hold the specimen in place. The pressure delivery system provides pressurized fluid on the sheet metal specimen from the bottom. The sealing prevents the fluid from leaking from the system during the testing. As the pressure varies and increases, the sheet metal specimen experiences different stages of deformation. The Bulge Test setup should also be equipped to a pressure sensor to measure the pressure and position sensor to measure the bulge depth. The stress-strain graph of the specimen is obtained since the stress and strain are estimated based on the pressure and bulge depth measured at different stages of deformation during the testing.
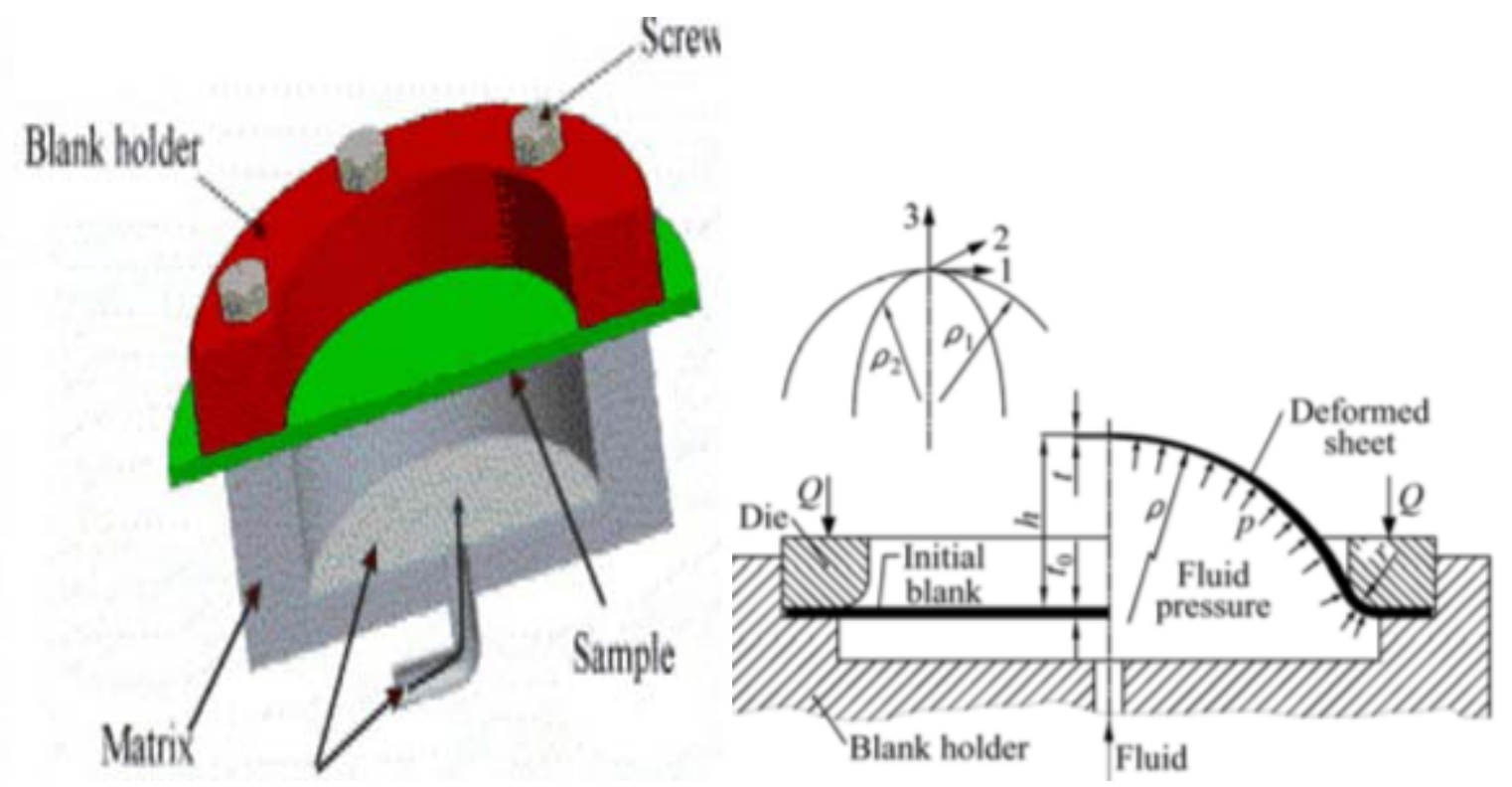

Figure 1: Schematic of bulge test apparatus; blank and deformed sheet metal tested [3]

For advanced simulations such as forming simulation of metal forming processes or crash simulation where plastic deformation plays a major role, having an accurate material model is highly desired. Thus, it is important to provide mechanical engineering students with the opportunities to observe more accurate testing methods that stress-strain graphs are obtained as opposed to traditional testing methods. A low-cost small size bulge test setup serves this purpose very well. 
The objective of this project is to engage a team of undergraduate students to utilize the fundamentals of mechanics along with Finite Element Simulation to design a small size low-cost Bulge Test Setup for instructional purposes.

While the project is a senior design project, it follows the following main educational goals:

1- The project aims to improve the ability of the students to design a realistic system and its components under realistic design requirements and constraints.

2- The projects aims to improve the ability of the students to apply fundamental of mathematics, and engineering (such as Mechanics of Materials, Plasticity and Metal Forming)

3- The project is to improve the ability of the students to apply modern engineering tools (such as SolidWorks, ABAQUS, Matlab, Excel) to analyze and design a realistic system and its components.

4- The project aims to improve the students' written and oral communication skills.

The educational goals of the project correlate closely with most of the ABET student outcomes (a-k), which are widely accepted in engineering education community. These outcomes have introduced and mandated by ABET for engineering programs to ensure the quality of engineering graduates. Projects similar to this project would help engineering educators to cover many student outcomes in senior design classes, which improve the quality of engineering education.

Two senior level students worked on this project over the course of two semesters under senior design project I and II classes. The students worked in Fall and Spring semesters on their projects. Unfortunately, no funding was available for the project. It is intended that the project complements the prior works of the other educators in improving senior design classes [4-7].

\section{Nomenclature}

$\varepsilon_{1}, \varepsilon_{2}=$ in-plane starins

$\varepsilon_{3}=$ out-of-plane strain (thickness strain)

$\varepsilon=$ biaxial strain

$t_{0}=$ initial thickness of sheet metal specimen

$t=$ final thickness of sheet metal specimen

$\varepsilon_{e f f}=$ effective strain

$\sigma_{\text {eff }}=$ effective stress

$K=K$-value of sheet metal

$n=n$-value of sheet metal

$V_{\text {before }}=$ volume of specimen before deformation

$V_{\text {after }}=$ volume of the specimen after deformation

$R=$ radius of die cavity

$\rho=$ radius of curvature of the bulge (or spherical sector)

$h=$ bulge height

$P=$ failure pressure

$V_{\text {internal }}=$ internal volume of bulge 


\section{Problem Statement}

The main purpose of this project is to engage a team of undergraduate engineering students to design a well-structure Bulge Test apparatus for instructional activities of the department. The apparatus should eventually take measurement of both the strain and stress that a specimen is experienced when subjected to hydraulic pressure. The apparatus should be designed so that undergraduate engineering students can be exposed to materials characterization experiments under biaxial deformation without necking effects.

The design needs are as follows:

- The setup needs be capable of testing materials with the strength as high as those of Advanced High Strength Steel (AHSS).

- The setup needs be capable of testing sheet metals as thick as $1 \mathrm{~mm}$.

- The setup needs to stay completely sealed and leak proof during testing.

- The fluid should not loss to the surrounding after material failure at the end of the testing.

- The pressure delivered needs to be variable and controllable.

- The pressure needs to be measured throughout the test.

- The bulge height needs to be measured throughout the test.

The design constraints are as follows:

- Due to limitation of the laboratory space, the apparatus size should be limited to $4 \mathrm{ft}$ in length, width and height.

- The total cost of the prototype should not exceed $\$ 1,500$.

- The setup should be compatible with hydraulic press available in the institution.

- The sensors to be selected should be compatible with National Instrument input board available in the institution for data acquisition.

- Due to sealing limitations, the pressure cannot exceed a maximum of $55 \mathrm{Mpa}$.

\section{Design Approach}

To achieve the objectives of the project, the students develop a reasonable design approach at the beginning of the project. The design approach developed is explained below.

First, the theory and the governing equations to the bulge test need to be researched and well understood. Then, based on the design needs and design constrains, the maximum allowable pressure needs to be calculated for the thickest and strongest sheet metal specimen. In the next step, the different components of the Bulge Test Setup need to be designed. The solid model of the components and assembly are built next. In the next step, the pressure sensor, and position sensors are selected considering the maximum allowable pressure. The sensors should also be compatible with the data acquisition system available in the institution. The sensors should be included in the solid models. Based on the pressure calculations, the pressure delivery system, which provides pressurized water to the specimen, needs to be designed. The seals should be designed to prevent any water leakage during testing. The performance of the setup needs to be validated based on forming simulation of the sheet metal specimen. The different components 
and assemblies that are under stress during testing need to be analyzed and simulated based on finite element method. The design needs to be documented at the end and a compressive final report needs to be written.

\section{Theory}

The goal of this section is for the team of students to derive formulations that help them to approach the problem systematically to finalize the size and capabilities of the bulge test setup. The first step of the design process is to calculate the maximum suitable pressure that needs to be delivered to the setup to deform the strongest thickest sheet metal specimen to be tested to failure. The industry considers failure to occur at thickness strain ( $\varepsilon 3)$ of $20 \%$ known as thinning. A negative sign is considered to illustrate the decrease in thickness of the sheet metal as it deforms to failure.

$$
\varepsilon_{3}=-0.2
$$

The thinning strain is defined as [8]

$$
\varepsilon_{3}=\ln \left(\frac{t}{t_{0}}\right)
$$

From (1) and (2), the final thickness $t$ is calculated as

$$
t=t_{0} \exp (-0.2)
$$

where $t_{0}$ is the initial thickness of sheet metal specimen. In a sheet metal forming process, volume preservation or incompressibility principle mandates [8]

$$
\varepsilon_{1}+\varepsilon_{2}+\varepsilon_{3}=0
$$

where $\varepsilon_{1}$ and $\varepsilon_{2}$ are in-plane strains, and $\varepsilon_{3}$ is out-of-plane (or thickness) strain. The bulge test deforms the sheet metal specimen with full symmetry; therefore the in-plane strains are equal (biaxial).

$$
\varepsilon_{1}=\varepsilon_{2}=\varepsilon
$$

where $\varepsilon$ is the biaxial strain in bulge test, which is the same as the in-plane $\varepsilon_{1}$ and $\varepsilon_{2}$. Substituting (5) into (4) yields

$$
2 \varepsilon+\varepsilon_{3}=0
$$

Substituting the thinning criterion of $20 \%$ presented in (1) into (6), the biaxial strain $\varepsilon$ is calculated as

$$
\varepsilon=0.1
$$

Substituting the strain values calculated in the Von-Mises equation, the effective strain is calculated as 0.365 [8].

$$
\varepsilon_{e f f}=\frac{\sqrt{2}}{3}\left[\left(\varepsilon_{1}-\varepsilon_{2}\right)+\left(\varepsilon_{1}-\varepsilon_{3}\right)+\left(\varepsilon_{2}-\varepsilon_{3}\right)\right]^{1 / 2}=0.365
$$


The Bulge Test Setup is designed based on the calculated effective strain of 0.365. Using power law, the effective stress $\sigma_{e f f}$ is calculated based on the calculated effective strain $\varepsilon_{e f f}$ and the material properties of the specimen [8].

$$
\sigma_{e f f}=K \varepsilon_{e f f}^{n}
$$

where $K$ is the strength coefficient (or K-value) and $n$ is the strain hardening exponent (or nvalue) of the material tested. The volume preservation can also be written for the entire sheet metal specimen. The volume preservation mandates that the volume of the specimen before deformation $V_{\text {before }}$ to be the same as the volume of the bulged specimen after deformation $V_{\text {after }}[8]$.

$$
V_{\text {before }}=V_{\text {after }}
$$

Before deformation, the sheet metal specimen is in a shape of a disc whose volume is simply determined in terms of the initial thickness of sheet metal specimen $t_{0}$ and the radius of the die cavity $R$ as

$$
V_{\text {before }}=\pi R^{2} t_{0}
$$

After deformation, the sheet metal deforms into a bulge-shaped spherical sector whose volume is determined by double integration as [8]

$$
V_{\text {after }}=2 \pi \rho h t
$$

where $\rho$ is the radius of curvature of the bulge (or the spherical sector), $h$ is the bulge height, and $t$ is the final thickness of the bulged specimen. Substituting (11) and (12) into volume preservation equation presented in (10) yields

$$
\pi R^{2} t_{0}=2 \pi \rho h t
$$

The radius of curvature of the bulge $\rho$ can be calculated in terms of the radius of the die cavity $R$ and the bulge depth $h$ as [8]

$$
\rho=\left(\frac{R^{2}+h^{2}}{2 h}\right)
$$

Substituting $\rho$ from (14) into (13), the bulge height $h$ is calculated in terms of the radius of the die cavity $R$, the initial thickness of sheet metal specimen $t_{0}$ and the final thickness of the bulged specimen $t$ as

$$
h=\sqrt{\left[\left(\frac{R^{2} t_{0}}{t}\right)-R^{2}\right]}
$$

The pressure $P$ to bulge the sheet metal comes from the equation derived by Marciniak [8] in terms of effective stress $\sigma_{e f f}$, bulge height $h$, radius of die cavity $R$, and initial thickness of sheet metal specimen $t_{0}$. 


$$
P=4 \sigma_{e f f} t_{0}\left(\frac{h}{R^{2}}\right)\left[\frac{1}{\left(1+\left(\frac{h}{R}\right)^{2}\right)^{2}}\right]
$$

The failure pressure $P$ can also be calculated in terms of materials properties ( $K$-value and $n$ value), bulge height $h$, radius of the die cavity $R$, and initial thickness of sheet metal specimen $t_{0}$ as

$$
P=4 K \varepsilon_{e f f}^{n} t_{0}\left(\frac{h}{R^{2}}\right)\left[\frac{1}{\left(1+\left(\frac{h}{R}\right)^{2}\right)^{2}}\right]
$$

The effective strain is considered as 0.365 , which is associated with the $20 \%$ thinning strain criterion widely used in industry.

Figure 2 and Figure 3 illustrate the effect of radius of the die cavity $R$ and initial thickness of the sheet metal $t_{0}$ on the failure pressure $P$, respectively. For this purpose, the materials properties are considered constant. The material properties of DP700/1000 are considered for this analysis $(K$-value $=1521 \mathrm{Mpa}$, and $n$-value $=0.09)$. As shown in Figure 2 , as the radius of the die increases, the pressure decreases. For the thicker specimen, a higher pressure is required for failure. This is also depicted in Figure 3, which shows a direct proportionality between the pressure and the initial thickness. As the initial thickness increases, the pressure increases linearly. For a smaller radius, a higher pressure is required. The radius of the die cavity proves to be more of a dominant factor in deciding the best possible specimen dimensions for the bulge test.

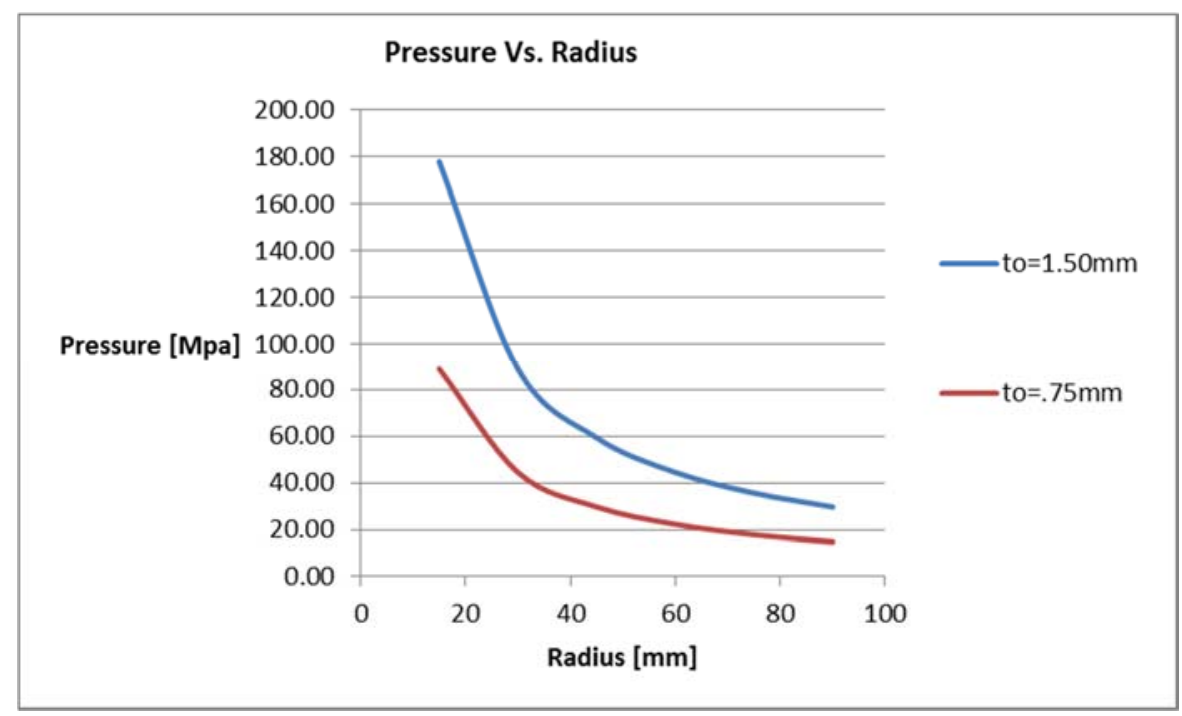

Figure 2: Effect of radius of die cavity on the failure pressure for different thickness of specimen 


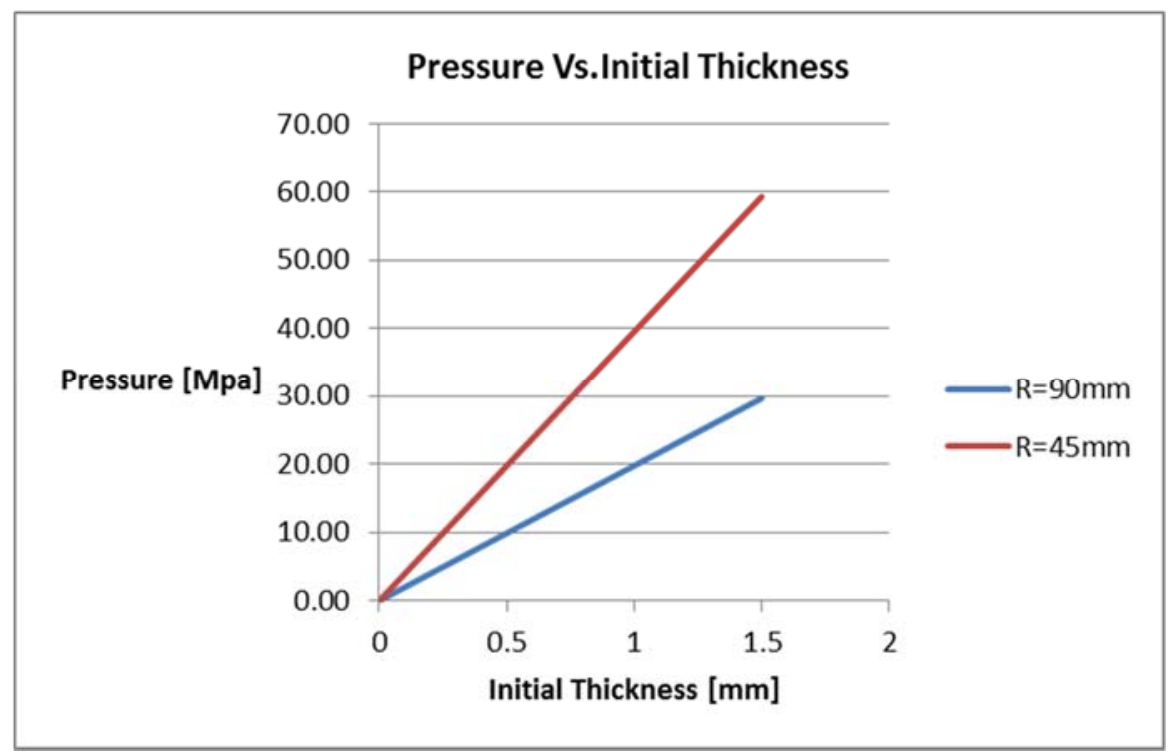

Figure 3: Effect of initial thickness of specimen on failure pressure for different radii of die cavity

Figure 4 shows that as $K$-value increases, the failure pressure increases linearly. $K$-value is the measure of material strength. Figure 4 also shows that as the $n$-value decreases, the failure pressure only slightly increases. The effect of $n$-value on the failure pressure is minimal when compared to the effect of $K$-value.

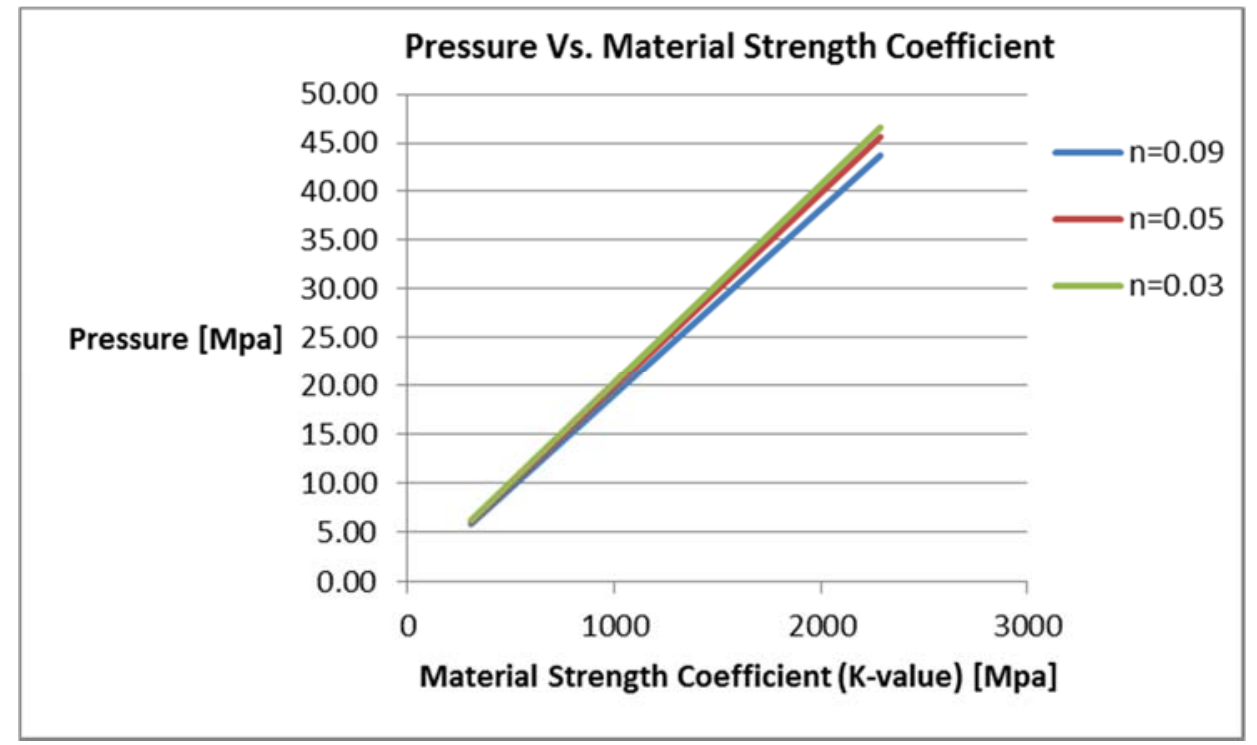

Figure 4: Effects of strain hardening coefficient ( $K$-value) and exponent ( $n$-value) on the failure pressure

After studying the pressure required to fail the specimen, the internal volume of the bulge $V_{\text {internal }}$ is calculated. This volume is used to estimate the amount of fluid needed for the bulge test. Considering the bulge as a spherical sector and using the triple integral with the correct 
limits of integrations, the following equation is derived which estimates the internal volume in terms of the radius of the die $R$, and bulge height $h$.

$$
V_{\text {int ernal }}=\left[\frac{1}{3}\left(R^{3}-(R-h)^{3}\right)\right]\left[\left(-\cos \left(\cos ^{-1}\left(\frac{R-h}{R}\right)\right)\right)+1\right](2 \pi)
$$

As shown in Figure 5, a solid model of a bulged sheet metal is built in SolidWorks with a radius of $90 \mathrm{~mm}$ and an initial thickness of $1.5 \mathrm{~mm}$ in order to check the accuracy of the equation above. The difference between the value that the derived equation estimates and that of the SolidWorks is within $1 \%$.

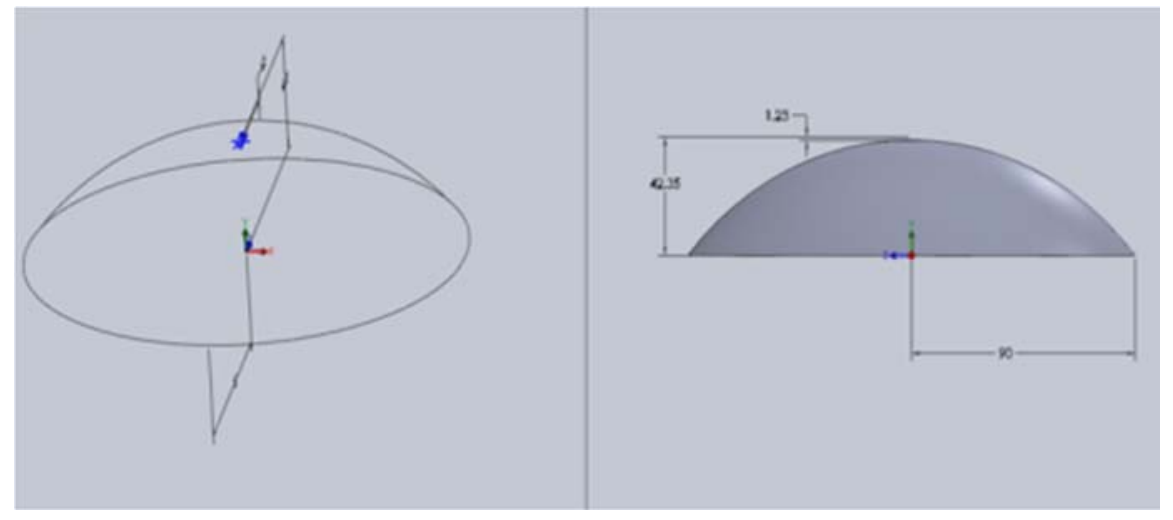

Figure 2: Solid model of the bulged specimen built for internal volume estimation

\section{Design considerations}

The maximum failure pressure needs to be calculated. There is a design constraint on the maximum pressure due to the fact that an affordable sealing needs to be selected to prevent water from leaking out during testing. The maximum allowable pressure is $55 \mathrm{Mpa}$ based on the design constraint. Considering a 30\% increase factor for the unpredicted pressure increases, the maximum allowable pressure becomes $42 \mathrm{Mpa}$. As analyzed previously, any increase in initial thickness of specimen, any increase in the material strength (or $K$-value), or any decrease in $n$ value cause an increase in the failure pressure that needs to be provided. For that purpose, a large initial thickness of $1.5 \mathrm{~mm}$, a high $K$-value of $2138 \mathrm{Mpa}$, and a low $n$-value of 0.09 are selected for failure pressure calculations for design purposes. For such selected values, the radius of the die is calculated as $90 \mathrm{~mm}$ using equations (15) and (17). However, the majority of the affordable seals that can withstand the maximum allowable pressure have internal diameters of less than $90 \mathrm{~mm}$. A design compromise is made in lowering the initial thickness to $0.8 \mathrm{~mm}$, but increasing the $K$-value to $2700 \mathrm{Mpa}$ and decreasing the n-value to 0.05 . For such values, the radius of the die cavity is calculated as $63.5 \mathrm{~mm}$, which is compatible with the relatively affordable seals available. For such radius of the die cavity, even thicker sheet metal samples can be attempted if samples with lower $K$-values are tested. 


\section{Components design}

Based on the values selected in the previous section, different components of the Bulge Test Setup are designed. The solid models of the components are built in SolidWorks. Figure 6 represents the sheet metal specimen.

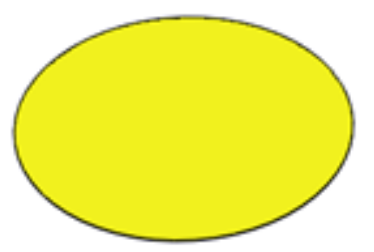

Figure 6: Sheet metal specimen for the Bulge Test Setup

Figure 7 depicts the lower die cavity, which consists of two cylinders. The specimen is placed on top of the small cylinder.

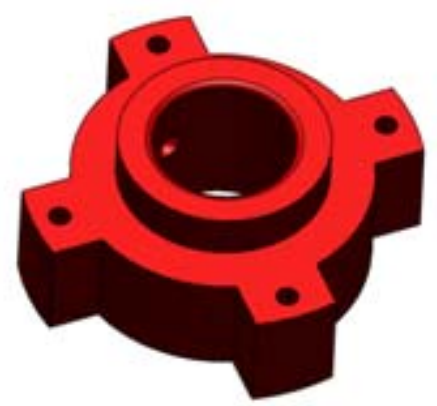

Figure 7: Lower die cavity

The seal shown in Figure 8 is placed around the neck of the small cylinder. The height of the seal is slightly less than the height of the small cylinder. This height difference prevents the contact between the top surface of the seal and the bottom surface of the upper die cavity during blank holding operation preventing any stress on the seal. The seal prevents water from leaking out of the any small opening when the specimen is clamped.
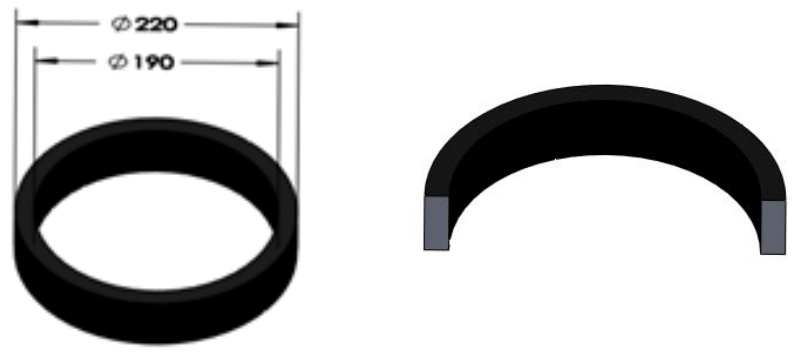

Figure 8: The seal with dimension lines (left) and section view (right)

Considering the amount of the water needed to fail the specimen and the diameter of the coupler, the height of the lower die cavity is calculated.

In order to record the pressure as the specimen bulges, a hole is placed on the side of the lower die cavity as shown in Figure 9. A half coupler is welded in the hole and the pressure sensor is 
then threaded inside the coupler. A torque wrench is used to accurately and safely tighten the pressure sensor into the half coupler.
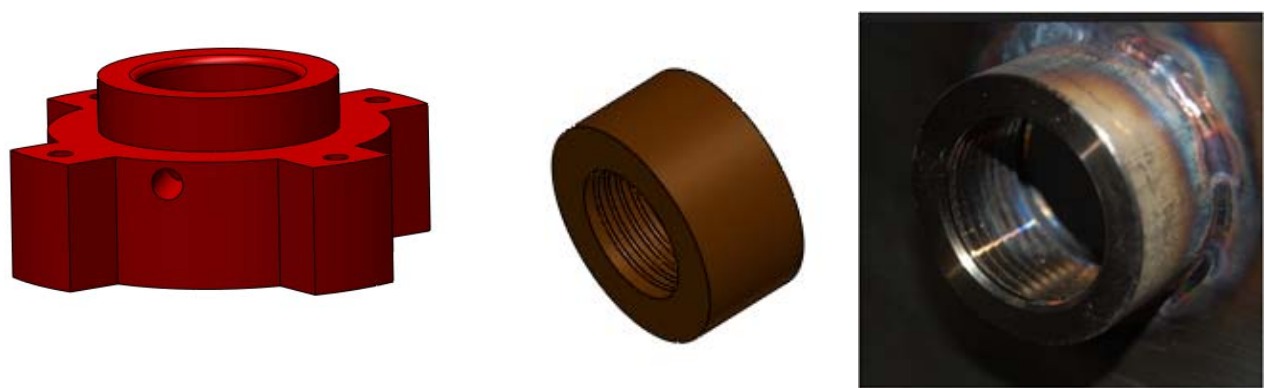

Figure 9: A hole in lower die cavity, half coupler, and the coupler welded to the side of lower die cavity

Figure 10 shows the solid model of the pressure sensor and the actual pressure sensor. An M300 series pressure sensor is selected for the Bulge Test Setup. This sensor measures pressure up to 69Mpa (10,000Psi). The sensor is compatible with the National Instrument data acquisition system available in the institution.
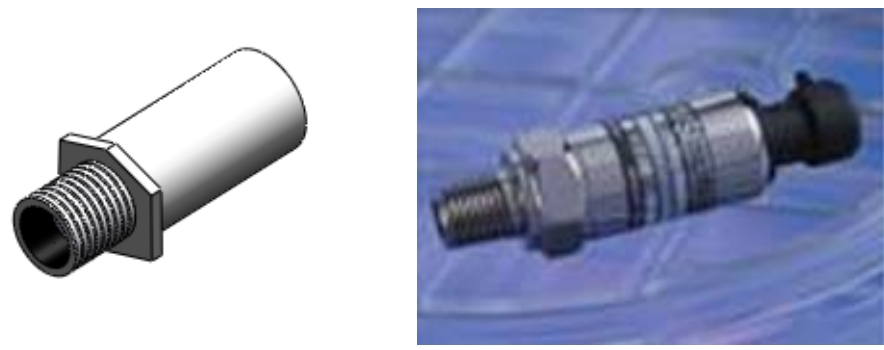

Figure 10: Solid model of pressure sensor and actual M300 Series pressure sensor

Figure 11 shows how the seal, specimen and pressure sensor are assembled into the lower die cavity. The pressure sensor is inserted to transmit the pressure measurement to the data acquisition system.
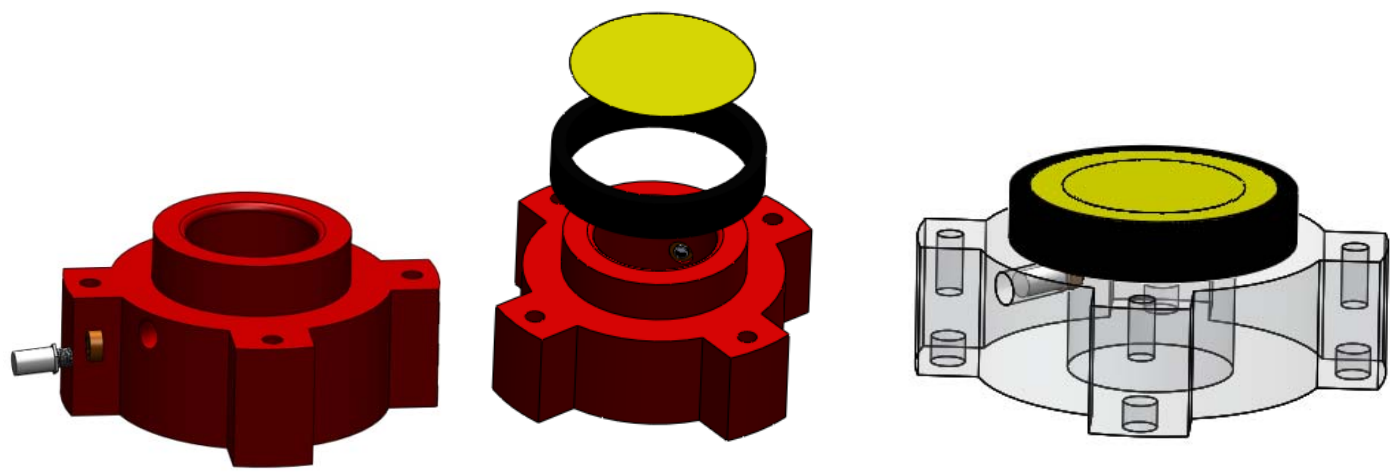

Figure 11: Pressure sensor assemblage to the lower die cavity

As shown in figure 12, the upper die cavity also contains two cylinders. The small top cylinder will be in contact with the press ram during blank holding operation. The blue highlighted region of the upper die cavity shows the area that the ram is inserted. As shown in the section view, a 
cap holding the position sensor is inserted into the green region. The position sensor cord is run through the blue region.
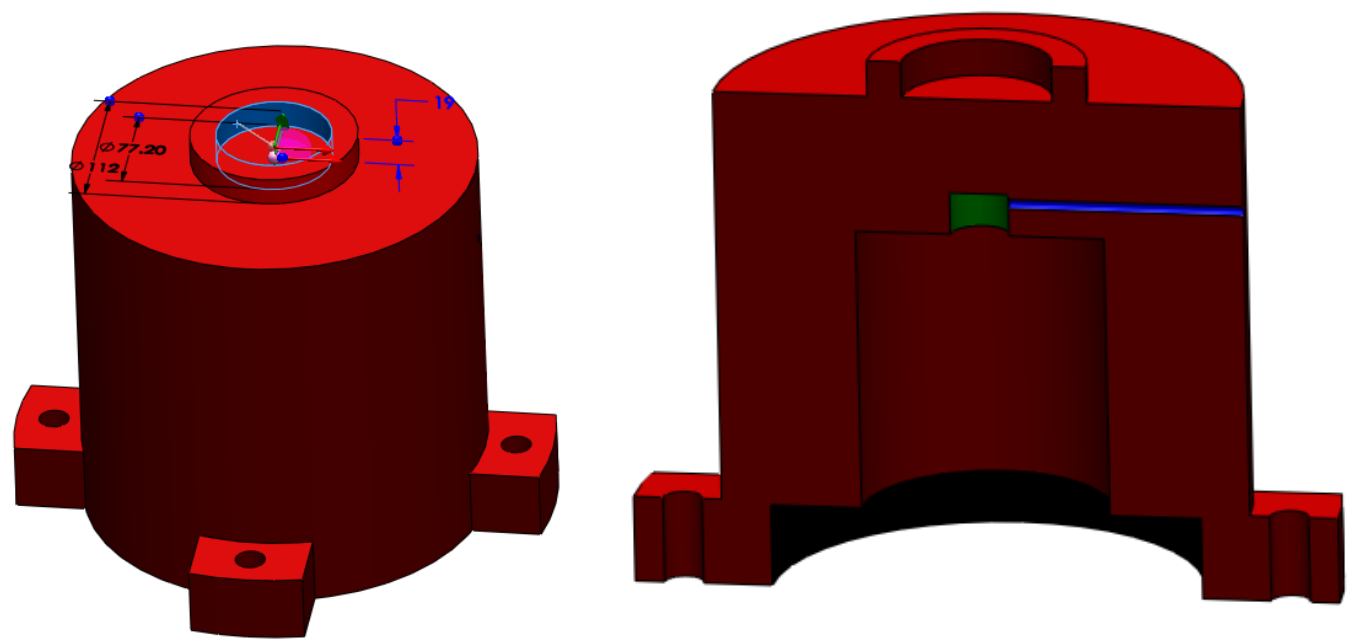

Figure 12: Top view (left) and section view (right) of the upper die cavity showing the location for the ram, position sensor, and its cord

The specimen deforms inside the deformation zone of the upper die cavity. The height of the deformation zone is figured based on the maximum bulge height of the sheet metal. The diameter of the deformation zone cavity is the same as that of the lower die cavity.

Figure 13 depicts the yellow region of the upper die cavity where the top surface of the specimen will be in contact. The diameter of the black region shown is the same as the outer diameter of the seal. The height of this region is calculated based on the specimen thickness and the height of the seal.
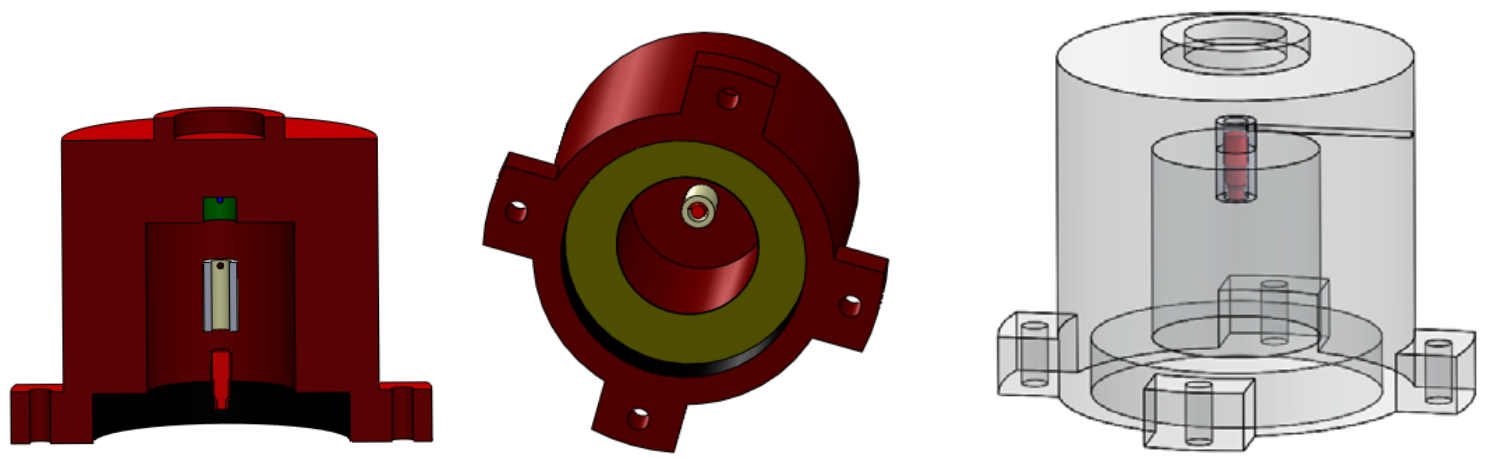

Figure 13: The location of where specimen is placed (yellow region) in the upper die cavity

The maximum bulge height when the specimen fails is estimated as $29.88 \mathrm{~mm}$. The ultrasonic position sensor shown in Figure 14 is selected, which has a measuring range of $35 \mathrm{~mm}-300 \mathrm{~mm}$. 


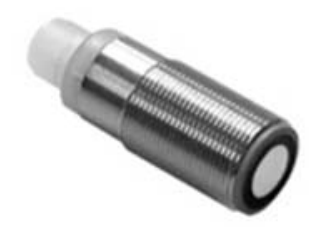

Figure 14: Ultrasonic position sensor for Bulge Test Setup

As shown in figure 15, a cap serving as a case for the position sensor is designed. The cap is threaded inside so that the position sensor can properly screw inside.
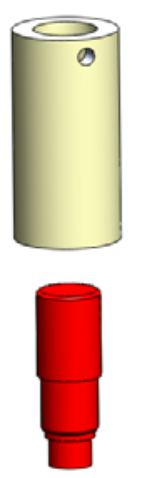

Figure 15: Position sensor cap, and position sensor

Figure 16 and Figure 17 show how the lower and upper dies are assembled. The pressure sensor, position sensor, seal, and specimen are clearly depicted in Figure 17.
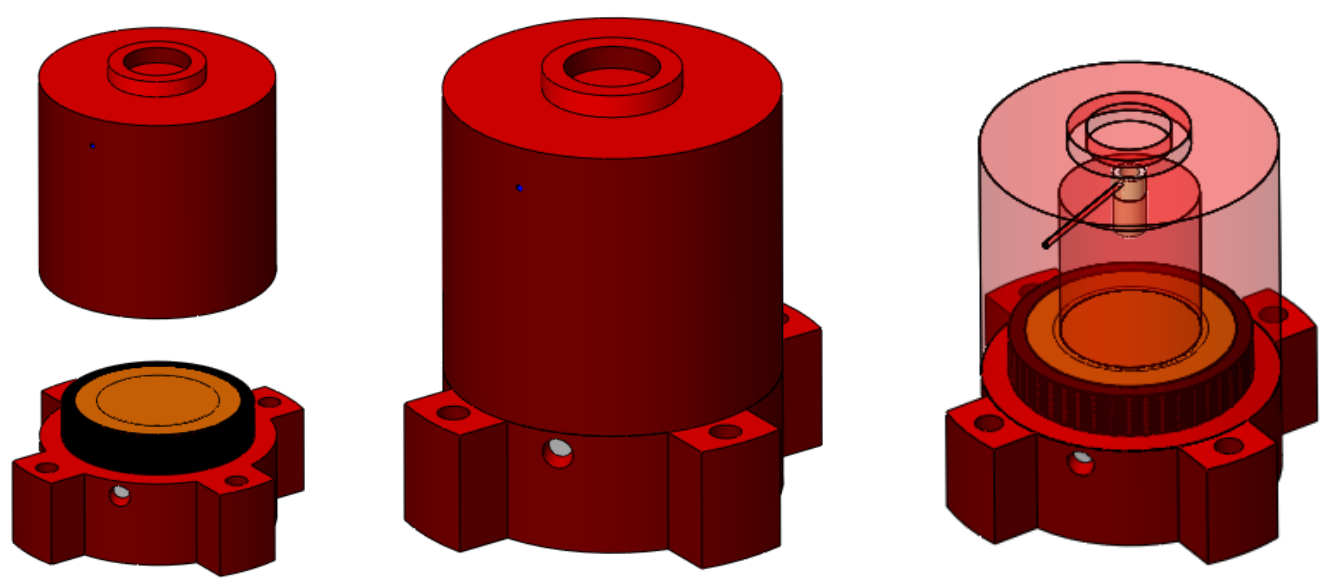

Figure 36: Lower and upper die assembly 

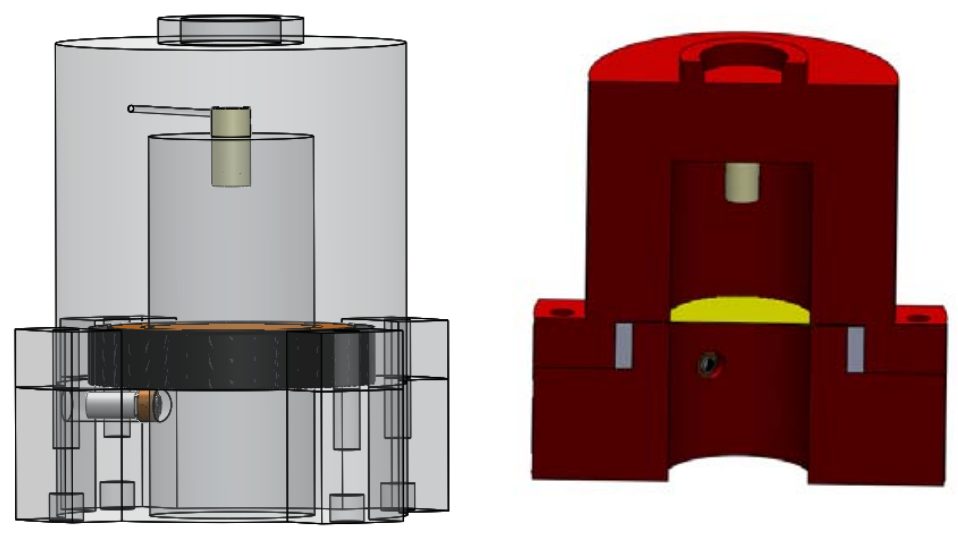

Figure 17: Pressure and position sensors, seal and specimen in lower and upper die assembly

In the Bulge Test Setup designed, a press on the top and a punch on the bottom are used to pressurize the water. As the press on the top moves downward, the Bulge Test Setup moves downward as well and the fluid becomes pressurized by to the stationary punch placed on the bottom. As shown in Figure 18, a seal is also wrapped around the neck of the punch to prevent water from leaking out of the bottom cavity.
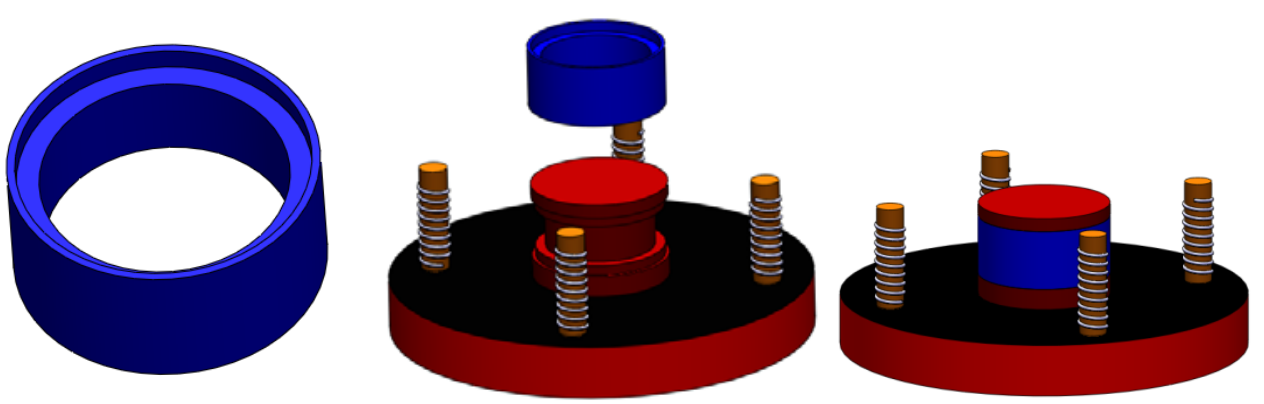

Figure 18: Punch, rods, spring, and seal.

The amount the setup needs to move downward to pressurize water is calculated based on the volume of the water needed to bulge the specimen up to failure. The rods and spring are used to hold the Bulge Test Setup as shown in Figure 19. 

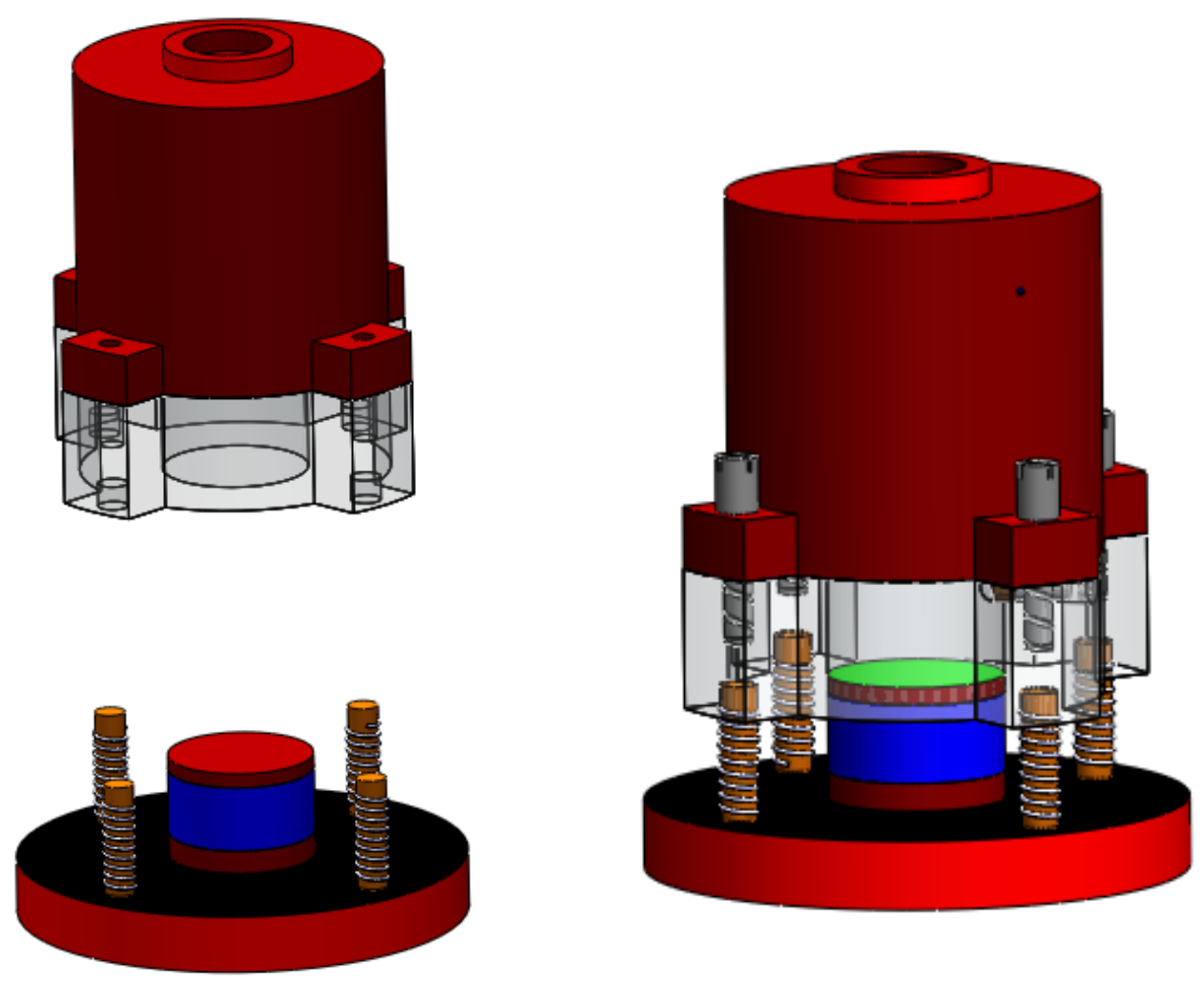

Figure 19: The Bulge Test Setup and punch before and after assembly

In order to keep the specimen from slipping, four bolts are designed to clamp the upper and lower die cavities together. The internal tension force needed is calculated [9]. A normal force greater than the internal tension force calculated is required to provide enough friction to prevent the specimen from slipping. After adding the bolts to the Bulge Test Setup, the system becomes slip proof. Figure 20 shows the solid model the setup tightened with the bolts designed.
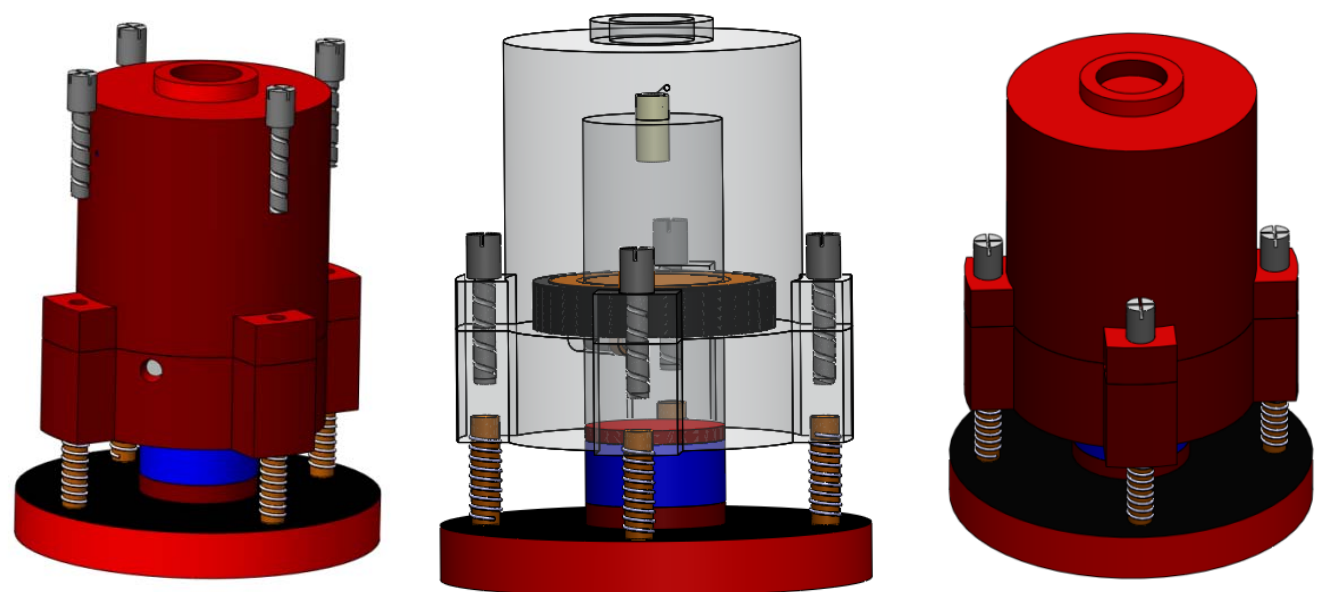

Figure 20: Bolt being inserted into both cavities 

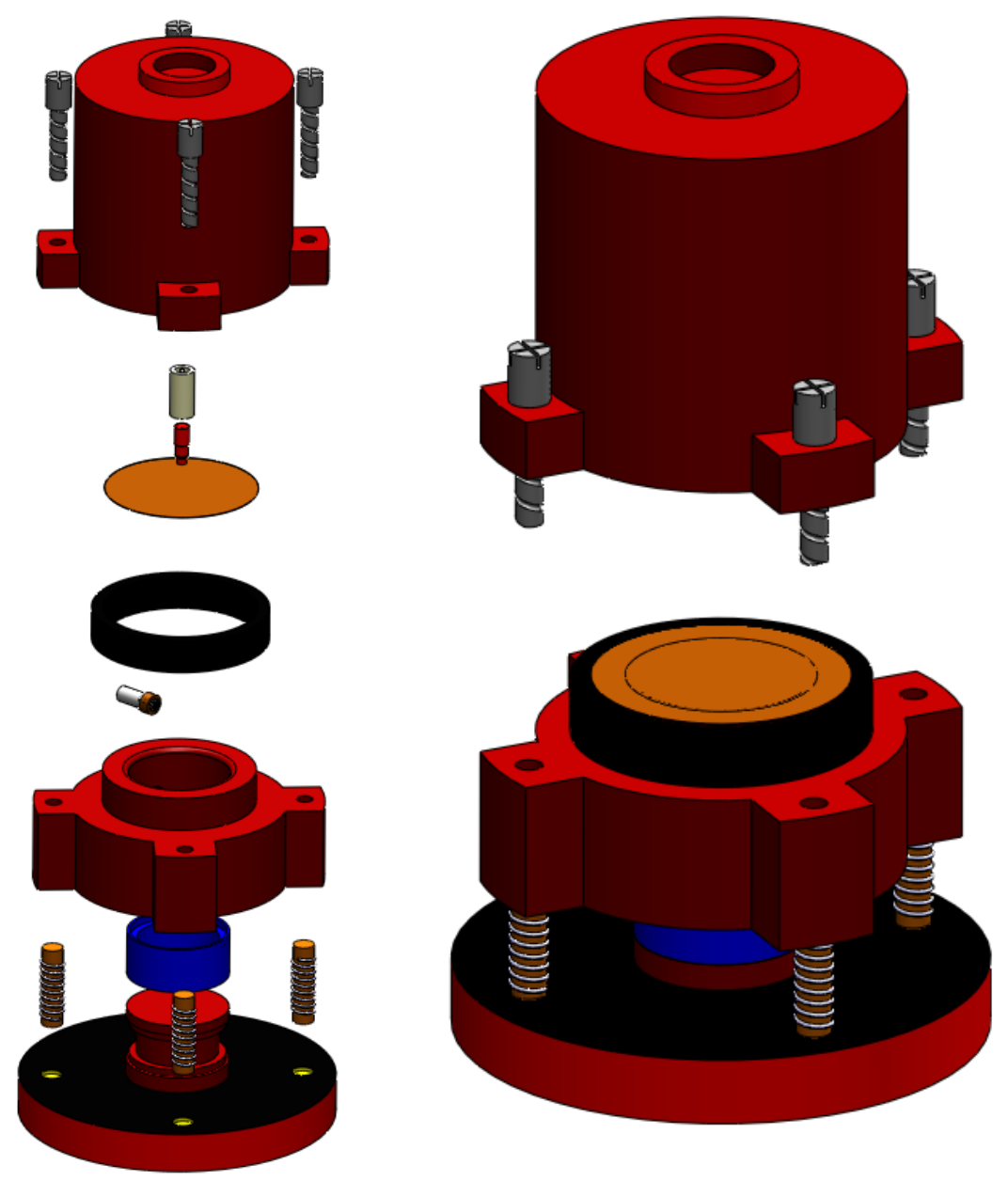

Figure 21-Solid Model of the Final Assembly in an exploded view

Once the design is finalized, the solid model of the final assembly is built. Figure 21 shows the solid model of the final assembly of the Bulge Test Setup designed. Figure 21 also depicts an exploded view of the Bulge Test setup finally assembled. The exploded view consists of the punch and base, springs and rods, punch's seal, lower die cavity, pressure sensor, half coupler, top cylinder's seal, specimen, position sensor, sensor holder, upper die cavity, and bolts.

Figure 22 depicts a section view of the system fully assembled. The final assembly of the system shown on the right of Figure 22 is then inserted into a press shown in Figure 23. Once the system is inserted into the press, the ram from the press would push the upper and subsequently the lower die pressurizing the water in the turquoise region. Some modifications to the press might be required to accommodate operation of the Bulge Test Setup. 

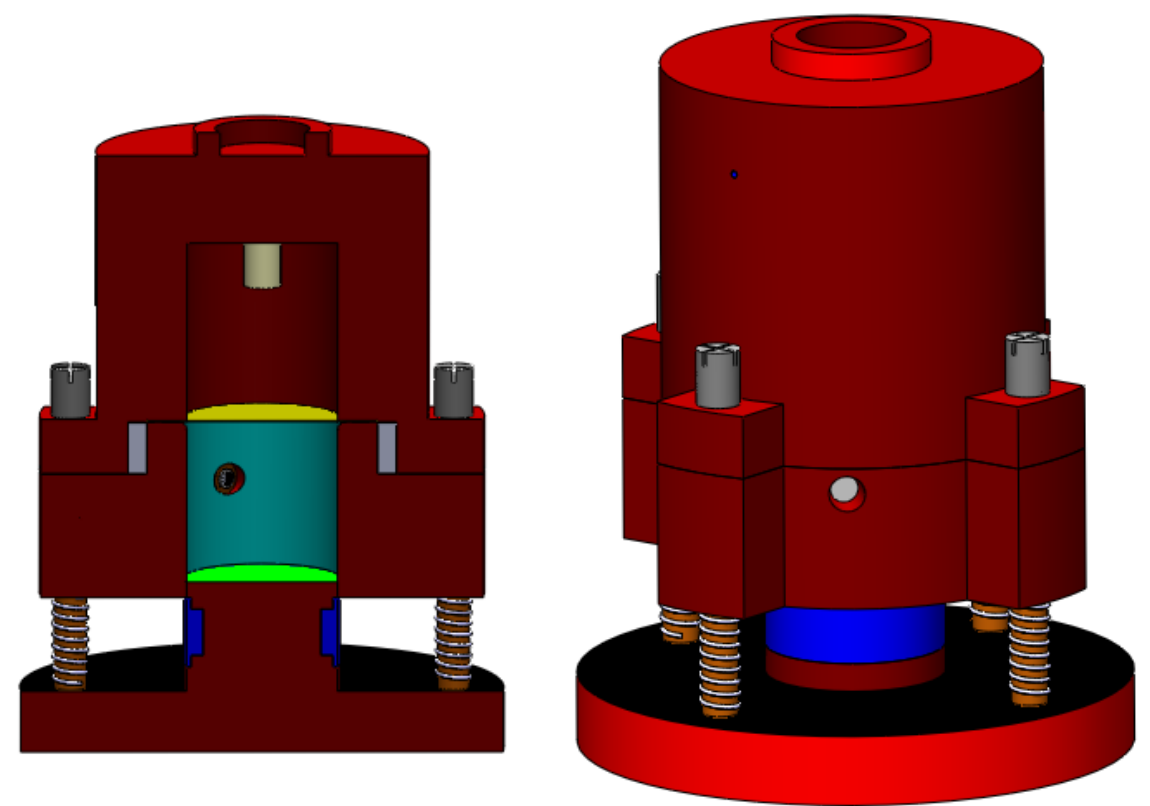

Figure 22 - Section view and Final Assembly

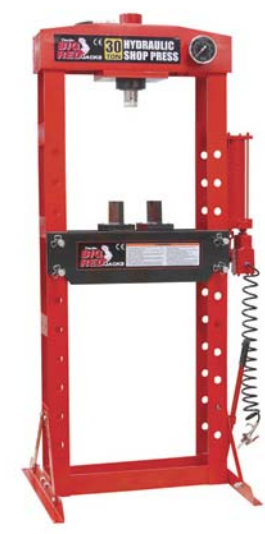

Figure 23: A 30 Ton press available for the Bulge Test Setup.

While to some extends, the design presented can be viewed as one possible solution to the problem, the design concept is mainly based on a specific design constraint that the die designed should be compatible with a hydraulic press available in the institution, which would pressurize water for the setup. Such constraint has shaped the design of the base, punch, and lower and upper die. If this constraint were released, the design would be different. In such case, as an alternative solution, the design team could design an independent pressure delivery system for the setup, which would feature noticeably different design configurations. 


\section{Estimated Cost}

After the design is finalized, and the solid model of the final assembly is built, the students estimates the cost to fabricate a working prototype of the apparatus. A major fraction of the total cost is associated with materials and supplies needed to be purchased. That includes pressure sensor, position sensor, springs and seals. A major fracture of the total cost is dedicated to machine shop and welding jobs. The cost table is presented in Table 1 . The total cost is estimated as $\$ 1,490$, which is lower than the maximum budget of $\$ 1,500$ specified as a design constraint.

Table 1- Cost Table

\begin{tabular}{|l|l|}
\hline Item / Service & Price \\
\hline Pressure Sensor & $\$ 129$ \\
Position Sensor & $\$ 225$ \\
Springs & $\$ 93.35$ \\
Lower Die Seal & $\$ 110.94$ \\
Punch Seal & $\$ 532.22$ \\
Manufacturing & $\$ 400$ \\
\hline Total & $\mathbf{\$ 1 4 9 0 . 5 1}$ \\
\hline
\end{tabular}

Due to budget limitation and the fact that the two-semester timeframe is not enough for the fabrication, the setup designed has not been built. In the institution, while students are highly encouraged to build their design, it is worth noting that the main focus of senior design projects is on design not fabrication.

\section{Student Learning Outcomes}

1- The project exposed a team of students to design process of a real world Bulge Test setup with realistic design requirements and design constraints.

2- The students developed a logical design approach to design the main components of the bulge test setup.

3- The students learned how to apply the fundamentals of mechanics to design for the main components such as lower die, upper die, sealing, and bolted joints.

4- The students learned how to build a solid model of the system, and how to run a finite element simulation to verify the design.

5- The students learn how to conduct a forming simulation to validate the performance of the setup designed.

6- The students gained hands-on experience working with different modern math and engineering software such as MATLAB, SolidWorks, ABAQUS, and etc.

7- The students gained valuable experience on how to select instrumentation for the apparatus. 
8- The students improved their oral communication skills by making weekly presentation to the audience of the senior design class and a faculty advisor.

9- The students improved their written communication skills by documenting the design, design verification and instrumentation selection.

10- The students had a chance to improve their project management skills by setting up project plan, time line, budge and cost table and etc.

In this project, the assessment has been mostly based on the observations of faculty advisor who meet with the student team once a week over the course of two consecutive semesters. In the weekly meetings, as the students present their progress and future plans, the advisor reviews their design and interacts with the students while assessing them. The students submit their report progressively in 4 revisions as their reports are improved gradually after rigorous grading by the faculty advisor. The final report is a strong assessment tool that the faculty uses for assessment purposes.

Faculty involved in this project received very positive feedback from the students who conducted the project. At the beginning of the project, the students thought that the topic was uncommon and unconventional. However, they became very interested in the topic as they read and learned more about the project. They were very convinced that they had the opportunity to work on a design project, which involved them in applying math and engineering fundamentals toward the design of a practical system. The students were very satisfied that they gained practical experience with modern engineering tools and software. The students noticed that their oral and written communication skills have improved remarkably as a result of this project. The students viewed the project as a challenge since many tasks needed to be completed in a short period of time. The students realized that while the course materials are very helpful, they are not enough to conduct real world projects. To this end they learned a great deal of extracurricular materials to successfully complete the project.

\section{Future Work}

While exact duplication of the project may not be suitable for future senior design projects, the following suggestions may be considered to change the project for future similar projects:

1- Some of the design requirements may change. For example, the maximum sheet metal strength or thickness may change to a lower or higher value.

2- Some of the design constrains may change. For instance, the size or weight constraint of the set up may change to a lower or higher value. The cost constraint may also change. More advanced pressure delivery system can be designed for higher cost.

3- The design can be further optimized and a physical prototype of the system can be built. The project can be assigned to the future students in continuation and or in portions for design modification and ultimate fabrication.

4- A data acquisition system that works with the system particularly with the pressure and position sensors selected can be designed for data collection and data analysis.

5- An automatic control system which controls the pressure applied can be designed and implemented. 


\section{Conclusions}

Solid mechanics and mechanics of metal forming fundamentals along with the state-of-art FEM simulations have been utilized to design a small-size low-cost Bulge Test setup for instructional purposes. The FEM investigations have validated the design since none of the apparatus components have experienced plastic deformation during testing while the specimen deforms plastically based on the design. A solid model of the Bulge Test setup designed has been built. The performance of the setup designed has been validated as adequate based on forming simulation. The cost is relatively reasonable. Valuable levels of knowledge have been gained through this undergraduate design project in the areas of solid mechanics, metal forming, FEM simulations, solid modeling, and design.

\section{References}

1. Hibbeler, R. C, Mechanics of Materials, Pearson Prentice Hall, $7^{\text {th }}$ edition, 2008.

2. Hosford, W. F., Caddell, R. M., Metal Forming Mechanics and Metallurgy, PTR Prentice Hall, $2^{\text {nd }}$ edition, 1993.

3. Nasser, A., Yadav, A., Pathak, P., and Altan, T., Determination of the flow stress of five AHSS sheet materials (DP 600, DP 780, DP 780-CR, DP 780-HY and TRIP 780) using the uniaxial tensile and the biaxial Viscous Pressure Bulge (VPB) tests, Journal of Materials Processing Technology, Vol. 210, No. 3, pp 429-436, 2010.

4. Alan, D. J., Magleby, S. P., Sorensen, C. D., and Todd, R. H., A Review of Literature on Teaching Engineering Design Through Project-Oriented Capstone Courses, Journal of Engineering Education, Vol. 86, No. 1, pp. 17-28, 1997.

5. Lackey, L.W., Jenkins, H.E., Mines, R.O., and Schultz, S.R., Utilizing Senior Capstone Design as an Instrument for Student and Faculty Assessment of Program Outcomes, 2009 ASEE Conference, Marietta, GA, paper, 2009006MIN, pp. 1-11, April 2009.

6. Todd, R.H., Sorensen, C. D., and Magleby, C. D., Designing a Capstone Course to satisfy industrial customers, Journal of Engineering Education, Vol. 82, No. 2, April 1993, pp. 92100.

7. Paliwal, M., Sepahpour, B., A Revised Approach for better Implementation of Capstone Senior Design Projects, 2012 ASEE, San Antonio, TX, AC 2012-5442, June 2012.

8. Marciniak, Z., Duncan, J.L., and Hu, S.J. Mechanics of Sheet Metal Forming, Oxford: Butterworth-Heinemann, 2002.

9. Omoba, F. Design of a Bulge Test Die, Senior Design Report, 2013. 